\title{
6-Bicycloaryl substituted (S)- and $(R)-5,6$-dihydro-2H-pyran-2-ones: Asymmetric synthesis, and anti-proliferative properties
}

\author{
Pınar Kasaplar ${ }^{\mathrm{a}}$, Özgür Yılmazer ${ }^{\mathrm{b}}$, Ali Çağır ${ }^{\mathrm{a}, *}$ \\ a İmir Institute of Technology, Faculty of Science, Department of Chemistry, Urla 35430, İzmir, Turkey \\ b Izmir Institute of Technology, Biotechnology and Bioengineering Central Research Laboratories, Urla 35430, Izmir, Turkey
}

\section{A R T I C L E I N F O}

\section{Article history:}

Received 26 September 2008

Revised 26 October 2008

Accepted 30 October 2008

Available online 5 November 2008

\section{Keywords:}

(R)-Goniothalamin

Cytotoxic activity

Conformationally constrained analogues

Cancer cell lines

\begin{abstract}
A B S T R A C T
$(R)$-Goniothalamin, is a member of styryl lactones, possesses selective cytotoxicity against cancer cell lines. In this work, replacement of styryl substituent with 2-naphthyl and 3-quinoyl gave new analogues which may have less conformational changes compared to the lead compound. Anti-proliferative tests indicated that 2-naphthyl substituted $(R)$-5,6-dihydro-2H-pyran-2-one has slightly better cytotoxicity than $(R)$-goniothalamin. To clarify the effect of 2-naphthyl substituent additional aryl substituted $(R)$ 5,6-dihydro-2H-pyran-2-ones have been synthesized enantioselectively and tested against PC-3 and MCF-7 cell lines.
\end{abstract}

(c) 2008 Elsevier Ltd. All rights reserved.

\section{Introduction}

One of the important issues of medicinal chemistry is to design compounds which selectively target the cancer cells preferably with no or minimized activity against normal cells. Goniothalamin (1), a naturally occurring styryl lactone, can be considered as a good lead compound for this purpose. Goniothalamin was first isolated from Cryptocarya caloneura in 1967, ${ }^{1}$ and later from the other natural sources (Fig. 1). ${ }^{2-7}$

Besides weak antibacterial and strong antifungal activity of $\mathbf{1}^{8}{ }^{8}$ $(R)$-goniothalamin (1a) has shown significant cytotoxicity against a variety of cancer cell lines like HeLa, HGC-27, MCF-7, T47D, MDA-MB-231, Caov-3, HL-60, NCI ADR, NCI 460, UACC62, 786-0, OVCAR03, PCO 3, and HT 29 in vitro. ${ }^{9-15}$ Pihie and coworkers have shown that, 1a has no significant cytotoxicity toward non-malignant cells, ${ }^{10}$ which implies that it has activity mainly in malignant cells. Its tumoricidal and tumoristatic effects have also been reported in vivo. ${ }^{16}$ Recent studies showed that several $(S)$-goniothalamin (1) $)$ derivatives, enantiomer of $\mathbf{1 a}$, also have similar cytotoxic activity against several tumor cell lines (Fig. 2). ${ }^{17}$

Although the mechanism of action of the goniothalamin derivatives is not fully understood yet, several studies demonstrated that 1a is a potential genotoxic substance. ${ }^{18}$ Besides the caspase9 activation and loss of mitochondrial membrane potential of the HL-60 leukemia cells, ${ }^{13}$ it is also responsible for an increase in

\footnotetext{
* Corresponding author. Tel.: +90 232 7507572; fax: +90 2327507509 .

E-mail address: alicagir@iyte.edu.tr (A. Çă̆ır).
}

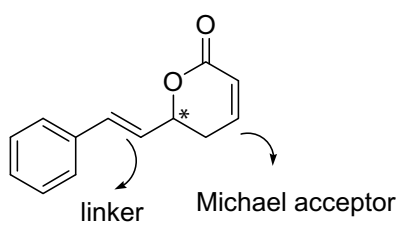

1

Figure 1. Structure of goniothalamin (1).<smiles>O=C1C=CC[C@H](/C=C/c2ccccc2)O1</smiles>

$1 \mathrm{a}$<smiles>O=C1C=CC[C@H](/C=C\c2ccccc2)O1</smiles>

2<smiles>O=C1C=CCC(/C=C/c2ccccc2)O1</smiles>

$1 b$<smiles>O=C1C=CC[C@H](COCc2ccccc2)O1</smiles>

3
Figure 2. Structures of $(R)$-goniothalamin (1a), $(S)$-goniothalamin $(\mathbf{1 b}),(R)$-goniothalamin analogues having linker cis- $\mathrm{C}=\mathrm{C}(\mathbf{2})$, and an ether (3). 
<smiles>O=C1C=CCC(c2ccc3ccccc3c2)O1</smiles>

$4 \mathrm{X}=\mathrm{C}$ $5 X=N$

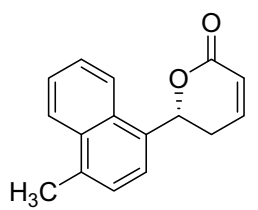

9

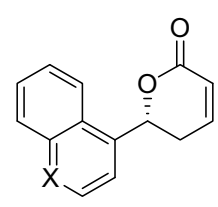
$6 X=C$
$7 X=N$

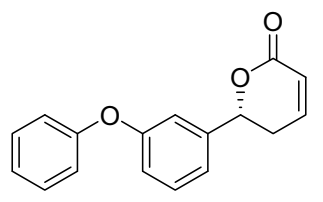

10

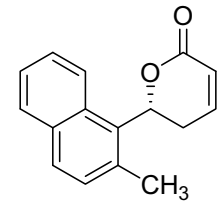

8

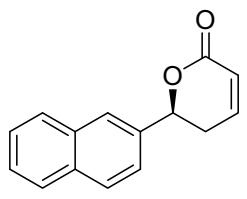

11
Figure 3. Structures of the proposed aryl substituted 5,6-dihydro-2H-pyran-2-ones (4-11).

Bax (pro-apoptotic protein) levels, ${ }^{12,14}$ and for the activation of p53 tumor suppressor protein. ${ }^{16}$

Because of the interesting biological activities of $\mathbf{1 a}$ and $\mathbf{1 b}$, several asymmetric synthesis routes have been developed mainly in the last decade. ${ }^{15,17,19-25}$ In this work, we represent the asymmetric synthesis and biological activities of three new conformationally constrained analogues of $(R)$ - and $(S)$-goniothalamin $(\mathbf{4}, \mathbf{5}$, and 11, Fig. 3) and five additional 6-aryl substituted (R)-5,6-dihydro$2 \mathrm{H}$-pyran-2-ones.

\section{Results and discussion}

Up to date, there is limited information about the activity structure relationship (SAR) of goniothalamin analogues. Two recently published works made contributions to the literature in this manner. de Fatima et al. showed that $(R)$-goniothalamin analogue, having cis-double bond between the carbons in the linker part (2), was 2-fold less cytotoxic compared to 1a towards the tested cancer cell lines except breast cell lines (MCF-7 and NCI ADR). In the same study another $(R)$-goniothalamin analogue, having ether functionality in the linker part (3), has been synthesized and evaluated against 8 different cancer cells. Although compound 3 shows 2-6 times lower cytotoxicity than 1a towards five of the selected cancer cells, 3 had comparatively better activity in the cell lines MCF7, OVCAR03, and PCO. ${ }^{15}$ It is believed that Michael acceptor and the trans-oriented double bond in the linker parts were essential for biological activity (Fig. 1). In this work, to better understand the role of the linker part, 2-napthyl and 3-quinoyl structures are proposed in the place of phenyl ring and trans-oriented linker part (4, $\mathbf{5}$, and 11). By this way, rotation around the single bond between the phenyl ring and linker will be restricted and it may form fully planar structure.

The enantioselective synthesis of target compounds has been accomplished by method developed by de Fatima et al. ${ }^{15}$ As shown in Table 1, asymmetric allylation of aldehydes $(\mathbf{1 2 a}-\mathbf{g})$ gave $(R)$ homoallylic alcohols (13a-g) in the presence of $\mu$-oxobis $(R$-binaphthoxy) (isopropoxy)titanium complex. When S-BINOL was used in the same reaction (S)-homoallylic alcohol (15) was produced. The enantiomeric excesses of the alcohols were determined by HPLC studies by employing Chiracel AD-H column ( $i$-propanol/ hexane mixtures as eluent). Yields and enantiomeric excesses were reported in Table 1 . In the second step purified alcohols were acrylated in the presence of acryloylchloride and triethylamine to form esters 14a-g and 16. Ring closing metathesis yielded the final products 4-11. Enantiomeric excesses of all products were calcu- lated on the basis of chiral HPLC studies as reported above. Through the synthesis, enantiomeric excesses of 3-phenoxyphenyl substituted derivatives $(\mathbf{1 3 g}, \mathbf{1 4 g}$, and $\mathbf{1 0}$ ) were almost same. On the other hand, when the substituent has been changed to a bicycloaryl group enantiomeric excess of the products fluctuated in all steps. The most dramatic changes in enantiomeric excesses have been observed during the synthesis of compounds $\mathbf{6}$ and $\mathbf{1 1}$. Although these two compounds tended to yield racemic mixtures in chromatography, enantiomeric enrichment was observed in the synthesis of compounds 5 and 7-9. Enantiomeric enrichment was first reported by Crooks et al., ${ }^{26}$ and such enrichment processes were reported for many different compounds, ${ }^{27}$ including molecules having benzylic hydrogen on the chiral carbon. ${ }^{28}$

As a reference in cytotoxicity tests, racemic goniothalamin (1) was prepared according to the literature, defined by Fatima et al. in the absence of $R$-BINOL (59) with $36 \%$ overall yield. Product was purified from $\mathrm{SiO}_{2}$ column and retention times of both enantiomers were monitored in HPLC Chiracel AD-H Column ( $i$ propanol/hexane $1: 9,1 \mathrm{~mL} / \mathrm{min} t_{1}=7.65 \mathrm{~min}$ and $t_{2}=7.98 \mathrm{~min}$ ). Then $(R)$-goniothalamin (1a) was synthesized by same procedure in the presence of $R$-BINOL starting from trans-cinnamaldehyde with $38 \%$ overall yield and $65 \%$ ee. Enantiomers were monitored in HPLC Chiracel AD-H Column under the same conditions and it was seen that the ratio of the peaks was different than that of racemic one and enantiomeric excess was calculated by using the area under these signals. Cytotoxic properties of synthesized compounds (1a and 4-10) were evaluated by MTT test on two cancer cell lines (PC-3 prostate cancer and MCF-7 human breast adenocarcinoma). Additional cytotoxicity tests for 1a, 4, and $\mathbf{1 1}$ were performed against two more cancer cell lines (DU-145, metastatic human prostate adenocarcinomas; LNCAP, lymph node metastasis of human prostate adenocarcinoma). As mentioned above, a Michael acceptor in lactone ring is crucial for cytotoxicity, similarly compounds $\mathbf{1 4 a - g}$ have also a Michael acceptor in their structures. Although they are not lactones they may also possesses anti-proliferative property. To better understand the importance of the lactone ring, compounds $\mathbf{1 4 b}-\mathbf{g}$ were also tested against PC-3 and MCF-7 cell lines. $\mathrm{IC}_{50}$ values of all MTT tests are listed in Table 2.

It is found that, all of the lactone products have more potent cytotoxicity over tested cell lines compared to their acrylate precursors. Interestingly, in case of acrylates there could not be found any structure-activity relationship, while anti-proliferative effects of lactone derivatives imply a structure dependent activity. Compound 14e was the most active one among the tested acrylate derivatives.

It is observed that, analogues $\mathbf{4}$ and $\mathbf{5}$ have slightly better anti-proliferative properties compared to $(R)$-goniothalamin which may be the result of either restriction of rotation around the styrene part of the molecule or steric effect of additional atoms in the 2-naphthyl and 3-quinoyl substituent. On the other hand compound $\mathbf{1 1}$ is four and two times less cytotoxicity in PC3 and MCF-7 cells respectively, compared to its enantiomer 4. This result was in agreement with those reported for $(R)$ - and (S)-goniothalamin. ${ }^{17}$

Sterically the most hindered analogue $\mathbf{1 0}$ has the weakest activity among the tested lactones. 1-Naphthyl substituted $(R)$ 5,6-dihydro-2H-pyran-2-ones $(\mathbf{6}, \mathbf{8}$, and $\mathbf{9})$ gave more promising results. Especially compound $\mathbf{9}$ is 80 times more potent compared to $(R)$-goniothalamin in PC-3 cells $\left(\mathrm{IC}_{50}=50 \mathrm{nM}\right)$, and 40 times more potent compared to $(R)$-goniothalamin in MCF-7 cells $\left(\mathrm{IC}_{50}=440 \mathrm{nM}\right)$. Structurally 1 -naphthyl derivatives seem much closer to the goniothalamin analogue which has a cisdouble bond in its linker domain (2). Contrarily it is discussed above that compound $\mathbf{2}$ has diminished cytotoxicity compared to $\mathbf{1 a}$. 
Table 1

Synthesis, conditions, yields and ee\% of compounds 4-11.

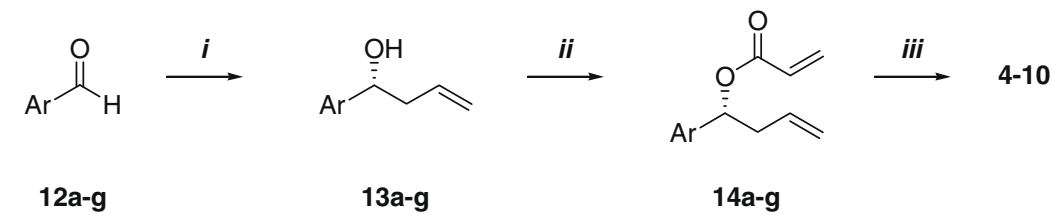<smiles>CC#CC=O</smiles><smiles>C#CC</smiles>

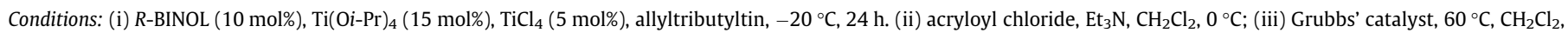
(iv) S-BINOL (10 mol\%), Ti(Oi-Pr) $)_{4}(15 \mathrm{~mol} \%), \mathrm{TiCl}_{4}(5 \mathrm{~mol} \%)$, allyltributyltin, $-20{ }^{\circ} \mathrm{C}, 24 \mathrm{~h}$

\begin{tabular}{|c|c|c|c|c|}
\hline Aldehydes & $\mathrm{Ar}$ & Alcohol (Yield, ee\%) ${ }^{\mathrm{a}}$ & Ester (Yield, ee\%) & Pyran-2-one (Yield, ee\%) \\
\hline $12 a$ & & 13a $(59,80)$ & $\mathbf{1 4 a}(53,79)$ & $4(88,76)$ \\
\hline 12b & & 13b, $(48,93)$ & $14 b,(54,92)$ & $5,(62,97)$ \\
\hline $12 c$ & & 13c, $(41,77)$ & 14c, $(69,44)$ & $6,(75,11)$ \\
\hline $12 d$ & & 13d, $(21,65)$ & 14d, $(56,100)$ & $7,(34,95)$ \\
\hline $12 f$ & & 13f, $(14,72)$ & $14 f,(56,66)$ & 9, $(87,93)$ \\
\hline $12 \mathrm{~g}$ & & 13g, $(11,76)$ & 14g, $(76,75)$ & 10, $(91,77)$ \\
\hline $12 a$ & & $\mathbf{1 5},(26,82)$ & 16, $(73,81)$ & $\mathbf{1 1},(73,43)$ \\
\hline
\end{tabular}

a Yields are reported based on purified products and ee\% are determined by Chiral HPLC column.

\section{Conclusion}

The enantioselective syntheses of nine new 6-aryl substituted (R)-5,6-dihydro-2H-pyran-2-ones were accomplished. Cytotoxic activities of these compounds showed that, restriction of the rotation around the single bond between the phenyl ring and double bond somehow causes an enhancement in the cytotoxicity. In addition, size of the substituent and the stereochemistry in the lactone ring are also important, $(R)$ enantiomer has lower $\mathrm{IC}_{50}$ value for 2-naphthyl substituted analogues. 1-Naphthyl substitution in the lactone ring dramatically enhanced the activity. Any additional methyl substitution in the naphthalene ring at position 2 and 4 produce highly cytotoxic compounds.

\section{Experimental}

\subsection{Chemistry part}

\subsubsection{General procedures}

Reagents were commercial grade and were used as supplied. Dichloromethane was distilled over calcium hydride. Reactions were monitored by TLC using Merck TLC plates (Silicagel 60 $\mathrm{F}_{254}$ ). Chromatographic separations were performed using 70230 mesh silica gel. Solvents, required for $\mathrm{SiO}_{2}$ column chromatography, were commercial grade and were used as supplied. Solvents, required for HPLC, were spectrometric grade and were used as supplied. ${ }^{1} \mathrm{H}$ NMR and ${ }^{13} \mathrm{C}$ NMR data were recorded on a Varian $400-$ MR (400 MHz) spectrometer. Chemical shifts for ${ }^{1} \mathrm{H}$ NMR and ${ }^{13} \mathrm{C}$ 
Table 2

$\mathrm{IC}_{50}(\mu \mathrm{M})$ values for tested compounds ${ }^{\mathrm{a}}$

\begin{tabular}{lllll}
\hline Entry & PC-3 & MCF-7 & DU-145 & LNCAP \\
\hline $1 \mathrm{a}$ & 4.0 & 19.0 & 12.0 & 28.0 \\
4 & 3.0 & 12.0 & 11.0 & 19.0 \\
5 & 2.5 & 3.2 & - & - \\
6 & 0.8 & 2.6 & - & - \\
7 & 9.8 & 32.5 & - & - \\
8 & 0.13 & 2.6 & - & - \\
9 & 0.05 & 0.44 & - & - \\
10 & 11 & $>50.0$ & - & - \\
11 & 12.0 & 28.0 & 15.0 & 37.0 \\
$14 \mathrm{~b}$ & 16.3 & 28.8 & - & - \\
$14 \mathrm{c}$ & 22.9 & $>50.0$ & - & - \\
$14 \mathrm{~d}$ & 15.0 & 13.2 & - & - \\
$14 \mathrm{e}$ & 8.8 & 10.4 & - & - \\
$14 \mathrm{f}$ & 45.0 & 33.1 & - & - \\
$14 \mathrm{~g}$ & $>50.0$ & $>50.0$ & - & - \\
\hline
\end{tabular}

a Concentrations, that are needed to inhibit 50\% of the cell growth, were determined from nonlinear regression analysis using the GraphPad Prism software $\left(r^{2}>0.9\right)$.

NMR are reported in $\delta$ (ppm). $\mathrm{CDCl}_{3}$ peaks were used as reference in ${ }^{1} \mathrm{H}$ NMR (7.26 ppm) and ${ }^{13} \mathrm{C}$ NMR (77.36 ppm), respectively. Optical rotations were measured with Optical Digital Polarimeter (SOLF) model WZZ-1S instrument. HPLC studies were performed by employing Chiracel AD-H column $(0.46 \times 150 \mathrm{~mm})$ on Agilent 1100 Series HPLC. GC-Mass spectra (EI) were measured on Agilent 6890N Network GC System equipped with a Quadrupole Mass Spectrometer (EI).

\subsection{2. (R)-(+)-1-(Naphthalen-2-yl)-but-3-en-1-ol (13a)}

In a $10 \mathrm{~mL}$ round-bottomed flask equipped with a magnetic stirring bar and a condenser, $24.8 \mathrm{mg}(14 \mu \mathrm{L}, 0.131 \mathrm{mmol})$ of $\mathrm{TiCl}_{4}$ was dissolved in $2.6 \mathrm{~mL}$ of dichloromethane. To this solution, $117.8 \mathrm{mg}$ $(120 \mu \mathrm{L}, 0.414 \mathrm{mmol})$ of $\mathrm{Ti}(\mathrm{O} i-\mathrm{Pr})_{4}$ was added under nitrogen atmosphere. The resulting solution was allowed to warm up to room temperature for $1 \mathrm{~h}$. and then $61 \mathrm{mg}(0.26 \mathrm{mmol})$ of silver (I) oxide was added. The mixture was stirred for $5 \mathrm{~h}$ without any exposure to direct day light. After dilution with $4.5 \mathrm{~mL}$ of dichloromethane, $150 \mathrm{mg}(0.524 \mathrm{mmol})$ of $R$-BINOL was added and stirred for $2 \mathrm{~h}$. The resulting mixture was cooled down to $-75^{\circ} \mathrm{C}$, and then treated sequentially with $409 \mathrm{mg}(2.62 \mathrm{mmol})$ of 2-naphthaldehyde and $953 \mathrm{mg}(893 \mu \mathrm{L}, 2.88 \mathrm{mmol})$ of allyltributyltin. The mixture was stirred for $16 \mathrm{~h}$ and allowed to warm up to room temperature. After the reaction was completed, the reaction mixture was filtered through a short pad of Celite, then quenched with saturated $\mathrm{NaHCO}_{3}$ solution, and extracted with $3 \times 30 \mathrm{~mL}$ of ethyl acetate. The organic extracts were combined and dried over $\mathrm{MgSO}_{4}$. After the removal of solvent under vacuum, purification of the crude by column chromatography on silica gel (ethyl acetate/hexanes, $1: 8$ ) furnished $309 \mathrm{mg}$ of $(R)-1$-(naphthalen-2-yl)but-3-en-1-ol (13a) as a colorless foam with $59 \%$ yield. $R_{\mathrm{f}}=0.65$ (ethyl acetate/hexanes, $1: 2) ;[\alpha]_{\mathrm{D}}^{30}+52.7\left(c\right.$ 3.00, $\left.\mathrm{CH}_{2} \mathrm{Cl}_{2}\right) ;{ }^{1} \mathrm{H}$ NMR $\left(400 \mathrm{MHz}, \mathrm{CDCl}_{3}\right) \delta 7.88-7.78(\mathrm{~m}, 4 \mathrm{H}), 7.53-7.44(\mathrm{~m}, 3 \mathrm{H}), 5.91-$ $5.77(\mathrm{~m}, 1 \mathrm{H}), 5.23-5.12(\mathrm{~m}, 2 \mathrm{H}), 4.90(\mathrm{t}, 1 \mathrm{H}, J=6.3 \mathrm{~Hz}), 2.68-2.54$ $(\mathrm{m}, 2 \mathrm{H}), 2.25(\mathrm{~s}, 1 \mathrm{H}) ;{ }^{13} \mathrm{C}$ NMR $\left(400 \mathrm{MHz}, \mathrm{CDCl}_{3}\right) \delta 141.58$, $134.68,133.59,133.28,128.52,128.28,128.00,126.44,126.13$, 124.83, 124.33, 118.81, 73.72, 44.04; MS (EI) $\mathrm{m} / \mathrm{z}$ calculated for $\mathrm{M}^{+}\left(\mathrm{C}_{14} \mathrm{H}_{14} \mathrm{O}\right)=198.1$; found: 198 (2\%), 179 (100\%), 166, 157, 129; Enantiomeric excess was found as $80 \%$ with HPLC-Chiracel AD-H column ( $i$-propanol/hexane $10: 90,1 \mathrm{~mL} / \mathrm{min} t_{1}=5.51 \mathrm{~min}$ 'major enantiomer', $t_{2}=5.97$ min 'minor enantiomer').

\subsection{3. $(R)-(+)-1-(Q u i n o l i n-3-y l)-b u t-3-e n-1-o l ~(13 b)$}

After the removal of solvent under vacuum, purification of the crude by column chromatography on silica gel (ethyl acetate/hex- anes, 1:6) furnished $253 \mathrm{mg}$ of $(R)-(+)-1$-(quinolin-3-yl)-but-3-en1 -ol (13b) as a yellow solid with $48 \%$ yield. $R_{\mathrm{f}}=0.22$ (ethyl acetate/ hexanes, 1:1); $[\alpha]_{\mathrm{D}}^{30}+28.21$ (c 2.53, EtOH); ${ }^{1} \mathrm{H}$ NMR $(400 \mathrm{MHz}$, $\left.\mathrm{CDCl}_{3}\right) \delta 8.72(\mathrm{~s}, 1 \mathrm{H}), 8.06(\mathrm{~s}, 1 \mathrm{H}), 8.00(\mathrm{~d}, 1 \mathrm{H}, J=8.22 \mathrm{~Hz}), 7.71$ $(\mathrm{d}, 1 \mathrm{H}, J=8.22 \mathrm{~Hz}), 7.65-7.58(\mathrm{~m}, 1 \mathrm{H}), 7.51-7.44(\mathrm{~m}, 1 \mathrm{H}), 5.85-$ $5.72(\mathrm{~m}, 1 \mathrm{H}), 5.14-5.06(\mathrm{~m}, 2 \mathrm{H}), 4.93-4.87(\mathrm{~m}, 1 \mathrm{H}), 4.15(\mathrm{br} \mathrm{s}$, $1 \mathrm{H}), 2.59-2.52(\mathrm{~m}, 2 \mathrm{H}) ;{ }^{13} \mathrm{C}$ NMR $\left(400 \mathrm{MHz}, \mathrm{CDCl}_{3}\right) \delta 149.19$, $147.15,136.83,133.66,132.78,129.20,128.66,127.71,127.69$, $126.70,118.71,71.06,43.56$; Enantiomeric excess was found as 93\% with HPLC-Chiracel AD-H column ( $i$-propanol/hexane 5:95, $1 \mathrm{~mL} / \mathrm{min} t_{1}=23.90 \mathrm{~min}$ 'minor enantiomer', $t_{2}=26.40 \mathrm{~min}$ 'major enantiomer').

\subsection{4. (R)-(+)-1-(Naphthalen-1-yl)-but-3-en-1-ol (13c)}

After the removal of solvent under vacuum, purification of the crude by column chromatography on silica gel (ethyl acetate/hexanes, $1: 8)$ furnished $214 \mathrm{mg}$ of $(R)-(+)-1-($ naphthalen-1yl)-but-3-en-1-ol (13c) as a light yellow solid with $41 \%$ yield. $R_{\mathrm{f}}=0.42$ (ethyl acetate/hexanes, 1:4); $[\alpha]_{\mathrm{D}}^{26}+84.35$ (c 2.14, $\left.\mathrm{CH}_{2} \mathrm{Cl}_{2}\right)$; ${ }^{1} \mathrm{H}$ NMR $\left(400 \mathrm{MHz}, \mathrm{CDCl}_{3}\right) \delta 8.07(\mathrm{~d}, 1 \mathrm{H}, J=7.18 \mathrm{~Hz})$, 7.92-7.87 (m, 1H), $7.79(\mathrm{~d}, 1 \mathrm{H}, J=8.08 \mathrm{~Hz}), 7.67(\mathrm{~d}, 1 \mathrm{H}$, $J=7.18 \mathrm{~Hz}), 7.57-7.46(\mathrm{~m}, 3 \mathrm{H}), 5.99-5.88(\mathrm{~m}, 1 \mathrm{H}), \quad 5.55-5.48$ $(\mathrm{m}, 1 \mathrm{H}), 5.26-5.16(\mathrm{~m}, 2 \mathrm{H}), 2.81-2.73(\mathrm{~m}, 1 \mathrm{H}), 2.66-2.56(\mathrm{~m}$, 1H), 2.37 (br s, $1 \mathrm{H})$; ${ }^{13} \mathrm{C}$ NMR $\left(400 \mathrm{MHz}, \mathrm{CDCl}_{3}\right) \delta 139.34$, $134.71,133.68,130.15,128.87,127.87,125.94,125.41$, $125.36,122.90,122.76,118.22,69.88,42.76$. MS (EI) $\mathrm{m} / z$ calculated for $\mathrm{M}^{+}\left(\mathrm{C}_{14} \mathrm{H}_{14} \mathrm{O}\right)=198.1$; found: 198 (2\%), 179 (100\%), 166, 157, 129; HPLC-Chiracel AD-H column was used and ee was found as 77\%, (i-propanol/hexane $5: 95,1 \mathrm{~mL} / \mathrm{min}$ $t_{1}=7.57 \mathrm{~min}$ 'minor enantiomer', $t_{2}=8.62 \mathrm{~min}$ 'major enantiomer').

\subsection{5. $(R)-(+)-1-(Q u i n o l i n-4-y l)-b u t-3-e n-1-o l ~(13 d)$}

After the removal of solvent under vacuum, purification of the crude by column chromatography on silica gel (ethyl acetate/hexanes, 1:6) furnished $73 \mathrm{mg}$ of $(R)-(+)-1$-(quinolin-4-yl)-but-3-en-1ol (13d) as a colorless oil with $21 \%$ yield. $R_{\mathrm{f}}=0.22$ (ethyl acetate/ hexanes, $1: 1) ;[\alpha]_{\mathrm{D}}^{21}+67.08\left(c \quad 0.73\right.$, EtOH); ${ }^{1} \mathrm{H}$ NMR $(400 \mathrm{MHz}$, $\left.\mathrm{CDCl}_{3}\right) \delta$ 8.71-8.65 (m, 1H), 8.06-8.00 (m, 1H), 7.97-7.91 (m, $1 \mathrm{H}), 7.65-7.58(\mathrm{~m}, 1 \mathrm{H}), 7.55-7.45(\mathrm{~m}, 2 \mathrm{H}), 5.94-5.83(\mathrm{~m}, 1 \mathrm{H})$, 5.52-5.46 (m, 1H), 5.18-5.10 (m, 2H), 4.30 (br s,1H), 2.74-2.65 $(\mathrm{m}, 1 \mathrm{H}), 2.57-2.47(\mathrm{~m}, 1 \mathrm{H}) ;{ }^{13} \mathrm{C}$ NMR $\left(400 \mathrm{MHz}, \mathrm{CDCl}_{3}\right) \delta 150.04$, $149.94,147.68,133.94,129.80,128.98,126.43,125.31,122.82$ $118.50,117.52,68.78,42.71$; Enantiomeric excess was found as $65 \%$ with HPLC-Chiracel AD-H column ( $i$-propanol/hexane 5:95, $1 \mathrm{~mL} / \mathrm{min} t_{1}=14.70 \mathrm{~min}$ 'major enantiomer', $t_{2}=17.09 \mathrm{~min}$ 'minor enantiomer').

\subsection{6. (R)-1-(2-Methylnaphthalen-1-yl)-but-3-en-1-ol (13e)}

After the removal of solvent under vacuum, purification of the crude by column chromatography on silica gel (ethyl acetate/ hexanes, $1: 8)$ furnished $104 \mathrm{mg}$ of $(R)-(+)-1-(2-$ methylnaphthalen-1-yl)-but-3-en-1-ol (13e) as a colorless oil with $19 \%$ yield. $R_{\mathrm{f}}=0.34$ (ethyl acetate/hexanes, $1: 6$ ); $[\alpha]_{\mathrm{D}}^{21}$ (could not be measured) (c 1.04, many different solvents were tried); ${ }^{1} \mathrm{H}$ NMR $\left(400 \mathrm{MHz}, \mathrm{CDCl}_{3}\right) \delta 8.67(\mathrm{~d}, 1 \mathrm{H}, J=8.61 \mathrm{~Hz}), 7.81(\mathrm{~d}, 1 \mathrm{H}$, $J=7.82 \mathrm{~Hz}), 7.51-7.39(\mathrm{~m}, 2 \mathrm{H}), 7.29-7.24(\mathrm{~m}, 1 \mathrm{H}), 5.96-5.84$ $(\mathrm{m}, 1 \mathrm{H}), 5.64-5.57(\mathrm{~m}, 1 \mathrm{H}), 5.21(\mathrm{ddd}, 1 \mathrm{H}, J=17.21,3.13$ and $1.56 \mathrm{~Hz}), 5.17-5.12(\mathrm{~m}, 1 \mathrm{H}), 3.60-2.96(\mathrm{~m}, 1 \mathrm{H}), 2.76-2.67(\mathrm{~m}$, $1 \mathrm{H}), 2.56(\mathrm{~s}, 3 \mathrm{H}), 2.20$ (br s, $1 \mathrm{H}) ;{ }^{13} \mathrm{C} \mathrm{NMR}\left(400 \mathrm{MHz}, \mathrm{CDCl}_{3}\right) \delta$ $135.30,135.08,133.38,132.99,131.26,129.49,128.70,128.03$, 125.63, 125.50, 124.64, 117.90, 71.54, 41.21, 21.00; Enantiomeric excess was found as $96 \%$ with HPLC-Chiracel AD-H column was used and ee was found as 93\%, ( $i$-propanol/hexane $5: 95,1 \mathrm{~mL} /$ $\min t_{1}=3.70 \mathrm{~min}$ 'minor enantiomer', $t_{2}=4.50 \mathrm{~min}$ 'major enantiomer'). 
4.1.7. (R)-(+)-1-(4-Methylnaphthalen-1-yl)-but-3-en-1-ol (13f)

After the removal of solvent under vacuum, purification of the crude by column chromatography on silica gel (ethyl acetate/hexanes, $1: 10$ ) furnished $71 \mathrm{mg}$ of $(R)-(+)-1-(4-m e t h y l n a p h t h a l e n-1-$ yl)-but-3-en-1-ol (13f) as a yellow oil with $14 \%$ yield. $R_{\mathrm{f}}=0.24$ (ethyl acetate/hexanes, 1:6); $[\alpha]_{\mathrm{D}}^{20}+57.72\left(\right.$ c $\left.0.71, \mathrm{CH}_{2} \mathrm{Cl}_{2}\right) ;{ }^{1} \mathrm{H}$ NMR $\left(400 \mathrm{MHz}, \mathrm{CDCl}_{3}\right) \delta 8.14-8.03(\mathrm{~m}, 2 \mathrm{H}), 7.58-7.51(\mathrm{~m}, 3 \mathrm{H})$, $7.34(\mathrm{~d}, 1 \mathrm{H}, J=7.43 \mathrm{~Hz}), 6.00-5.89(\mathrm{~m}, 1 \mathrm{H}), 5.55-5.49(\mathrm{~m}, 1 \mathrm{H})$, 5.26-5.15 (m, 2H), 2.81-2.73 (m, 1H), $2.70(\mathrm{~s}, 3 \mathrm{H}), 2.66-2.57(\mathrm{~m}$, $1 \mathrm{H}), 2.11$ (br s, $1 \mathrm{H}) ;{ }^{13} \mathrm{C} \mathrm{NMR}\left(400 \mathrm{MHz}, \mathrm{CDCl}_{3}\right) \delta 137.51,134.89$, $134.04,132.85,130.37,126.21,125.67,125.36,124.98,123.48$, $122.55,118.22,69.96,42.85,19.58$; Enantiomeric excess was found as $72 \%$ with HPLC-Chiracel AD-H column ( $i$-propanol/hexane $5: 95,1 \mathrm{~mL} / \mathrm{min} t_{1}=6.80 \mathrm{~min}$ 'major enantiomer', $t_{2}=7.10 \mathrm{~min}$ 'minor enantiomer').

\subsection{8. $(R)-(+)-1-(3-P h e n o x y p h e n y l)-b u t-3-e n-1-o l ~(13 g)$}

After the removal of solvent under vacuum, purification of the crude by column chromatography on silica gel (ethyl acetate/hexanes, 1:14) furnished $72 \mathrm{mg}$ of $(R)-(+)-1-(3-$ phenoxyphenyl)-but3-en-1-ol $(\mathbf{1 3 g})$ as a colorless oil with $11 \%$ yield. $R_{\mathrm{f}}=0.12$ (ethyl acetate/hexanes, $1: 10) ;[\alpha]_{\mathrm{D}}^{22}+31.66\left(c \quad 0.72, \mathrm{CH}_{2} \mathrm{Cl}_{2}\right) ;{ }^{1} \mathrm{H}$ NMR $\left(400 \mathrm{MHz}, \mathrm{CDCl}_{3}\right) \delta 7.38-7.28(\mathrm{~m}, 3 \mathrm{H}), 7.17-7.08(\mathrm{~m}, 2 \mathrm{H}), 7.06-$ $7.00(\mathrm{~m}, 3 \mathrm{H}), 6.92$ (ddd, $1 \mathrm{H}, J=8.22,2.74$ and $1.17 \mathrm{~Hz}$ ), 5.86-5.74 $(\mathrm{m}, 1 \mathrm{H}), 5.19-5.15(\mathrm{~m}, 1 \mathrm{H}), 5.15-5.13(\mathrm{~m}, 1 \mathrm{H}), 4.74-4.68(\mathrm{~m}$, $1 \mathrm{H}), 3.43-2.57(\mathrm{~m}, 2 \mathrm{H}), 2.23(\mathrm{br} d, 1 \mathrm{H}, J=2.74 \mathrm{~Hz}) ;{ }^{13} \mathrm{C} \mathrm{NMR}$ $\left(400 \mathrm{MHz}, \mathrm{CDCl}_{3}\right) \delta 157.33,157.12,146.00,134.15,129.72$, $129.70,123.23,120.58,118.84,118.64,117.83,116.30,72.87$, 43.79; Enantiomeric excess was found as $76 \%$ with HPLC-Chiracel AD-H column (i-propanol/hexane $5: 95,1 \mathrm{~mL} / \mathrm{min} t_{1}=6.90 \mathrm{~min}$ 'major enantiomer', $t_{2}=7.80 \mathrm{~min}$ 'minor enantiomer').

\subsection{9. (S)-(-)-1-(Naphthalen-2-yl)-but-3-en-1-ol (15)}

Catalyst was prepared by using $S$-BINOL instead of $R$-BINOL, and same procedure was applied for aldehyde 12a. After the removal of solvent under vacuum, purification of the crude by column chromatography on silica gel (ethyl acetate/hexanes, 1:8) furnished $133 \mathrm{mg}$ of $(S)-(-)-1$-(naphthalen-2-yl)-but-3-en-1-ol (15) as a light yellow solid with $26 \%$ yield. $R_{\mathrm{f}}=0.42$ (ethyl acetate/hexanes, $1: 4) ;[\alpha]_{\mathrm{D}}^{26}-47.87\left(\right.$ c $\left.1.32, \mathrm{CH}_{2} \mathrm{Cl}_{2}\right) ;{ }^{1} \mathrm{H}$ NMR $\left(400 \mathrm{MHz}, \mathrm{CDCl}_{3}\right) \delta$ 7.88-7.78 (m, 4H), 7.53-7.44 (m, 3H), 5.91-5.77 (m, 1H), 5.23$5.12(\mathrm{~m}, 2 \mathrm{H}), 4.90(\mathrm{t}, 1 \mathrm{H}, J=6.3 \mathrm{~Hz}), 2.68-2,54(\mathrm{~m}, 2 \mathrm{H}), 2.25(\mathrm{~s}$, $1 \mathrm{H}) ;{ }^{13} \mathrm{C}$ NMR $\left(400 \mathrm{MHz}, \mathrm{CDCl}_{3}\right) \delta 141.58,134.68,133.59,133.28$, $128.52,128.28,128.00,126.44,126.13,124.83,124.33,118.81$, 73.72, 44.04; MS (EI) $m / z$ calculated for $\mathrm{M}^{+}\left(\mathrm{C}_{14} \mathrm{H}_{14} \mathrm{O}\right)=198,1$; found: 198 (2\%), 179 (100\%), 166, 157, 129; Enantiomeric excess was found as $82 \%$ with HPLC-Chiracel AD-H column ( $i$-propanol/ hexane $10: 90,1 \mathrm{~mL} / \mathrm{min} t_{1}=5.51 \mathrm{~min}$ 'minor enantiomer', $t_{2}=5.95$ min 'major enantiomer').

\subsubsection{0. $(R)-(+)-1-($ Naphthalen-2-yl)but-3-enyl acrylate (14a)}

A solution of $302 \mathrm{mg}$ ( $1.523 \mathrm{mmol})$ of 13a in $3.0 \mathrm{~mL}$ of dichloromethane was cooled down to $0{ }^{\circ} \mathrm{C}$; then $248 \mathrm{mg}$ of acryloyl chloride $(223 \mu \mathrm{L}, 2.74 \mathrm{mmol})$ and $554.6 \mathrm{mg}$ of triethyl amine $(770 \mu \mathrm{L}$, $5.48 \mathrm{mmol}$ ) were sequentially added. The mixture was warmed to room temperature and stirred for $22 \mathrm{~h}$ under nitrogen atmosphere. The resulting mixture was filtered through a short pad of Celite, poured into water, and the product was extracted with $3 \times$ $25 \mathrm{~mL}$ of dichloromethane. The combined organic layer was concentrated under reduced pressure and purification of this residue by column chromatography on silica gel (ethyl acetate/hexane, $1: 8)$ gave $204.8 \mathrm{mg}$ of $(R)-1$-(naphthalen-2-yl)but-3-enyl acrylate (14a) with $53 \%$ yield. $R_{\mathrm{f}}=0.63$ (ethyl acetate/hexanes, $1: 4$ ); $[\alpha]_{\mathrm{D}}^{25}$ +67.46 (c 2.05, $\mathrm{CH}_{2} \mathrm{Cl}_{2}$ ); ${ }^{1} \mathrm{H}$ NMR $\left(400 \mathrm{MHz}, \mathrm{CDCl}_{3}\right) \delta 7.88-7.70$ $(\mathrm{m}, 4 \mathrm{H}), 7.53-7.41(\mathrm{~s}, 3 \mathrm{H}), 6.44(\mathrm{~d}, 1 \mathrm{H}, J=17.3 \mathrm{~Hz}), 6.24-6.12(\mathrm{~m}$, $1 \mathrm{H}), 6.09-6.00(\mathrm{~m}, 1 \mathrm{H}), 5.84(\mathrm{~d}, 1 \mathrm{H}, J=10.4 \mathrm{~Hz}), 5.80-5.67(\mathrm{~m}$,
1H), 5.16-5.00 (m, 2H), 2.85-2.63 (m, 2H); ${ }^{13} \mathrm{C}$ NMR (400 MHz, $\left.\mathrm{CDCl}_{3}\right) \delta 165.74,137.64,133.49,133.45,133.44,131.28,128.92$, $128.65,128.41,128.01,126.56,126.45,126.10,124.62,118.56$, 75.86, 41.00; $\mathrm{MS}$ (EI) $\mathrm{m} / \mathrm{z}$ calculated for $\mathrm{M}^{+}\left(\mathrm{C}_{17} \mathrm{H}_{16} \mathrm{O}_{2}\right)=252.1$; found: 252 (2\%), 224, 178, 156 (100\%), 128, 68; Enantiomeric excess was found as $79 \%$ with HPLC-Chiracel AD-H column ( $i$-propanol/hexane $10: 90,1 \mathrm{~mL} / \mathrm{min} t_{1}=2.80 \mathrm{~min}$ 'major enantiomer', $t_{2}=3,50$ min 'minor enantiomer').

\subsubsection{1. (R)-(+)-1-(Quinolin-3-yl)-but-3-enyl acrylate (14b)}

Purification of the crude product by column chromatography on silica gel (ethyl acetate/hexane, 1:8) gave $171 \mathrm{mg}$ of $(R)-(+)-1-$ (quinolin-3-yl)-but-3-enyl acrylate (14b) as a yellow solid with $54 \%$ yield. $R_{\mathrm{f}}=0.26$ (ethyl acetate/hexanes, $\left.1: 4\right) ;[\alpha]_{\mathrm{D}}^{18}+74.37(c$ 1.71, EtOH); ${ }^{1} \mathrm{H}$ NMR $\left(400 \mathrm{MHz}, \mathrm{CDCl}_{3}\right) \delta 8.92(\mathrm{~d}, 1 \mathrm{H}, J=2.35 \mathrm{~Hz})$ 8.11-8.06 (m, 2H), $7.79(\mathrm{~d}, 1 \mathrm{H}, J=8.22 \mathrm{~Hz}), 7.67$ (ddd, $1 \mathrm{H}$, $J=8.22,6.65$, and $1.56 \mathrm{~Hz}), 7.55-7.48(\mathrm{~m}, 1 \mathrm{H}), 6.43(\mathrm{dd}, 1 \mathrm{H}$, $J=17.61$ and $1.56 \mathrm{~Hz}), 6.20-6.11(\mathrm{~m}, 1 \mathrm{H}), 6.09-6.04(\mathrm{~m}, 1 \mathrm{H}), 5.83$ (dd, $1 \mathrm{H}, J=10.56$ and $1.56 \mathrm{~Hz}), 5.78-5.66(\mathrm{~m}, 1 \mathrm{H}), 5.12-5.04(\mathrm{~m}$, $2 \mathrm{H}), 2.86-2.77(\mathrm{~m}, 1 \mathrm{H}), 2.75-2.66(\mathrm{~m}, 1 \mathrm{H}) ;{ }^{13} \mathrm{C}$ NMR $(400 \mathrm{MHz}$, $\left.\mathrm{CDCl}_{3}\right) \delta 165.08,149.21,147.74,133.69,132.48,132.18,131.35$, $129.53,129.13,128.04,127.77,127.42,126.82,118.89,73.34$, 40.26; Enantiomeric excess was found as $92 \%$ with HPLC-Chiracel AD-H column ( $i$-propanol/hexane $1: 99,1 \mathrm{~mL} / \mathrm{min} t_{1}=19.50 \mathrm{~min}$ 'major enantiomer', $t_{2}=21.50 \mathrm{~min}$ 'minor enantiomer').

\subsubsection{2. (R)-(+)-1-(Naphthalen-1-yl)-but-3-enyl acrylate (14c)}

Purification of the crude product by column chromatography on silica gel (ethyl acetate/hexane, 1:8) gave $186 \mathrm{mg}$ of $(R)-(+)-1-$ (naphthalen-1-yl)-but-3-enyl acrylate (14c) with 69\% yield. $R_{\mathrm{f}}=0.63$ (ethyl acetate/hexanes, 1:4); $[\alpha]_{\mathrm{D}}^{26}+7.92$ (c 2.12, EtOAc) was detected for $73 \%$ ee in the second synthesis); ${ }^{1} \mathrm{H}$ NMR $\left(400 \mathrm{MHz}, \mathrm{CDCl}_{3}\right) \delta 8.16(\mathrm{~d}, 1 \mathrm{H}, J=8.27 \mathrm{~Hz}), 7.88(\mathrm{~d}, 1 \mathrm{H}$, $J=8.27 \mathrm{~Hz}), 7.81(\mathrm{~d}, 1 \mathrm{H}, J=8.27 \mathrm{~Hz}), 7.61-7.44(\mathrm{~m}, 4 \mathrm{H}), 6.71-$ $6.66(\mathrm{~m}, 1 \mathrm{H}), 6.47(\mathrm{dd}, 1 \mathrm{H}, J=17.46$ and $1.84 \mathrm{~Hz}), 6.21(\mathrm{dd}, 1 \mathrm{H}$, $J=17.46$ and $10.11 \mathrm{~Hz}), 5.89-5.74(\mathrm{~m}, 2 \mathrm{H}), 5.15-5.04(\mathrm{~m}, 2 \mathrm{H})$, 2.87-2.81 (m, 2H); ${ }^{13} \mathrm{C}$ NMR (400 MHz, $\left.\mathrm{CDCl}_{3}\right) \delta 165.59,136.08$, $134.04,133.69,131.21,130.55,129.15,128.77,128.73,126.54$, $125.89,125.45,124.11,123.39,118.23,72.73,40.60$; Enantiomeric excess was found as $44 \%$ with HPLC-Chiracel AD-H column ( $i$-propanol/hexane $5: 95,1 \mathrm{~mL} / \mathrm{min} t_{1}=3.21 \mathrm{~min}$ 'major enantiomer', $t_{2}=4.22$ min 'minor enantiomer').

\subsubsection{3. (R)-(-)-1-(Quinolin-4-yl)-but-3-enyl acrylate (14d)}

Purification of the crude product by column chromatography on silica gel (ethyl acetate/hexane, 1:8) gave $43 \mathrm{mg}$ of $(R)-(+)-1$-(quinolin-4-yl)-but-3-enyl acrylate (14d) as a yellow oil with $56 \%$ yield. $R_{\mathrm{f}}=0.15$ (ethyl acetate/hexanes, $1: 4$ ); $[\alpha]_{\mathrm{D}}^{28}-5.50\left(\right.$ c 2.30, $\mathrm{CH}_{2} \mathrm{Cl}_{2}$ ); ${ }^{1} \mathrm{H}$ NMR $\left(400 \mathrm{MHz}, \mathrm{CDCl}_{3}\right) \delta 8.90(\mathrm{~d}, 1 \mathrm{H}, J=4.30 \mathrm{~Hz}) 8.18-8.07$ $(\mathrm{m}, 2 \mathrm{H}), 7.73$ (ddd, $1 \mathrm{H}, J=8.22,6.65$, and $1.17 \mathrm{~Hz}), 7.60(\mathrm{ddd}, 1 \mathrm{H}$, $J=8.22,7.04$, and $1.17 \mathrm{~Hz}), 7.43(\mathrm{~d}, 1 \mathrm{H}, J=3.91 \mathrm{~Hz}), 6.62(\mathrm{dd}, 1 \mathrm{H}$, $J=7.43$ and $5.48 \mathrm{~Hz}), 6.49(\mathrm{dd}, 1 \mathrm{H}, J=17.22$ and $1.56 \mathrm{~Hz}), 6.22$ (dd, $1 \mathrm{H}, J=17.22$ and $10.56 \mathrm{~Hz}), 5.90(\mathrm{dd}, 1 \mathrm{H}, J=10.56$ and $1.17 \mathrm{~Hz}), 5.83-5.71(\mathrm{~m}, 1 \mathrm{H}), 5.13-5.05(\mathrm{~m}, 2 \mathrm{H}), 2.85-2.71(\mathrm{~m}$, $2 \mathrm{H}) ;{ }^{13} \mathrm{C}$ NMR $\left(400 \mathrm{MHz}, \mathrm{CDCl}_{3}\right) \delta 165.08,150.07,148.39,145.45$, $132.41,131.67,130.46,129.28,128.01,126.88,125.19,122.91$, $118.74,117.83,71.21,40.01$; Enantiomeric excess was found as $100 \%$ with HPLC-Chiracel AD-H column ( $i$-propanol/hexane 1:99, $1 \mathrm{~mL} / \mathrm{min} t_{1}=11.50 \mathrm{~min}$ 'single peak').

\subsubsection{4. (R)-(+)-1-(2-Methylnaphthalen-1-yl)-but-3-enyl acrylate (14e)}

Purification of the crude product by column chromatography on silica gel (ethyl acetate/hexane, $1: 10)$ gave $81 \mathrm{mg}$ of $(R)-(+)-1-(2-$ methylnaphthalen-1-yl)-but-3-enyl acrylate (14e) as a light yellow oil with $62 \%$ yield. $R_{\mathrm{f}}=0.47$ (ethyl acetate/hexanes, $1: 4$ ); $[\alpha]_{\mathrm{D}}^{18}$ 
$+15.15\left(\mathrm{c} 0.80, \mathrm{CH}_{2} \mathrm{Cl}_{2}\right) ;{ }^{1} \mathrm{H}$ NMR $\left(400 \mathrm{MHz}, \mathrm{CDCl}_{3}\right) \delta 8.51(\mathrm{~d}, 1 \mathrm{H}$, $J=8.61 \mathrm{~Hz}), 7.82(\mathrm{~d}, 1 \mathrm{H}, J=7.82 \mathrm{~Hz}), 7.71(\mathrm{~d}, 1 \mathrm{H}, J=8.61 \mathrm{~Hz})$, 7.54-7.48 (m, 1H), 7.46-7.41 (m, 1H), $7.29(\mathrm{~d}, 1 \mathrm{H}, J=8.22 \mathrm{~Hz})$, $6.42(\mathrm{dd}, 1 \mathrm{H}, J=17.22$ and $1.56 \mathrm{~Hz}), 6.18(\mathrm{dd}, 1 \mathrm{H}, J=17.22$ and $10.56 \mathrm{~Hz}$ ), $5.84-5.72(\mathrm{~m}, 2 \mathrm{H}), 5.14$ (ddd, $1 \mathrm{H}, J=17.22,3.13$, and $1.56 \mathrm{~Hz}), 5.10-5.05(\mathrm{~m}, 1 \mathrm{H}), 3.19-3.09(\mathrm{~m}, 1 \mathrm{H}), 2.92-2.83(\mathrm{~m}$, $1 \mathrm{H}), 2.68(\mathrm{~s}, 3 \mathrm{H}) ;{ }^{13} \mathrm{C}$ NMR $\left(400 \mathrm{MHz}, \mathrm{CDCl}_{3}\right) \delta 165.42,134.28$, $133.54,133.27,132.01,131.08,130.72,129.34,128.84,128.53$, $128.46,125.73,124.54,117.92,117.90,72.83$, 39.11, 20.92; Enantiomeric excess was found as $100 \%$ with HPLC-Chiracel AD-H column ( $i$-propanol/hexane $1: 99,0.7 \mathrm{~mL} / \mathrm{min} t_{1}=4.00 \mathrm{~min}$ single peak).

\subsubsection{5. $(R)-(+)-1-(4-M e t h y l n a p h t h a l e n-1-y l)-b u t-3-e n y l$ acrylate (14f)}

Purification of the crude product by column chromatography on silica gel (ethyl acetate/hexane, $1: 12$ ) gave $50 \mathrm{mg}$ of $(R)-(+)-$ 1-(4-methylnaphthalen-1-yl)-but-3-enyl acrylate (14f) as a light yellow oil with $56 \%$ yield. $R_{\mathrm{f}}=0.45$ (ethyl acetate/hexanes, $1: 8$ ); $\left([\alpha]_{\mathrm{D}}^{31}+13.33\right.$ (c 2.73, $\left.\mathrm{CH}_{2} \mathrm{Cl}_{2}\right)$ was detected for $78 \%$ ee in the second synthesis); ${ }^{1} \mathrm{H}$ NMR $\left(400 \mathrm{MHz}, \mathrm{CDCl}_{3}\right) \delta 8.21-8.16(\mathrm{~m}, 1 \mathrm{H})$, 8.07-8.03 (m, 1H), 7.60-7.52 (m, 2H), $7.48(\mathrm{~d}, 1 \mathrm{H}, J=7.04 \mathrm{~Hz})$, $7.32(\mathrm{dd}, 1 \mathrm{H}, J=7.43$ and $0.78 \mathrm{~Hz}), 6.70-6.65(\mathrm{~m}, 1 \mathrm{H}), 6.46(\mathrm{dd}$, $1 \mathrm{H}, J=17.22$ and $1.56 \mathrm{~Hz}), 6.20(\mathrm{dd}, 1 \mathrm{H}, J=17.22$ and $10.56 \mathrm{~Hz}$ ), $5.88-5.76(\mathrm{~m}, 2 \mathrm{H}), 5.13(\mathrm{dd}, 1 \mathrm{H}, J=3.13$ and $1.56 \mathrm{~Hz}), 5.09-5.04$ $(\mathrm{m}, 1 \mathrm{H}), 2.87-2.81(\mathrm{~m}, 2 \mathrm{H}), 2.69(\mathrm{~d}, 3 \mathrm{H}, J=0.78 \mathrm{~Hz}) ;{ }^{13} \mathrm{C}$ NMR $\left(400 \mathrm{MHz}, \mathrm{CDCl}_{3}\right) \delta 165.36,134.64,133.96,133.56,132.84$, $130.85,130.39,128.56,126.02,125.92,125.49,124.92,123.63$, 117.87, 72.51, 40.32, 19.58; Enantiomeric excess was found as $66 \%$ with HPLC-Chiracel AD-H column ( $i$-propanol/hexane 1:99, $1 \mathrm{~mL} / \mathrm{min} t_{1}=2.80 \mathrm{~min}$ 'major enantiomer', $t_{2}=3.16 \mathrm{~min}$ 'minor enantiomer').

\subsubsection{6. $(R)-(+)-1-(3-P h e n o x y p h e n y l)-b u t-3-e n y l$ acrylate (14g)}

Purification of the crude product by column chromatography on silica gel (ethyl acetate/hexane, 1:12) gave $61 \mathrm{mg}$ of $(R)-(+)-1-(3-$ phenoxyphenyl)-but-3-enyl acrylate $(\mathbf{1 4 g})$ as a light yellow oil with $76 \%$ yield. $R_{\mathrm{f}}=0.50$ (ethyl acetate/hexanes, $1: 8$ ); $[\alpha]_{\mathrm{D}}^{21}+28.67$ (c $\left.0.43, \mathrm{CH}_{2} \mathrm{Cl}_{2}\right) ;{ }^{1} \mathrm{H}$ NMR $\left(400 \mathrm{MHz}, \mathrm{CDCl}_{3}\right) \delta 7.38-7.28(\mathrm{~m}, 3 \mathrm{H})$, 7.15-7.08 (m, 2H), 7.06-7.00 (m, 3H), 6.92 (ddd, $1 \mathrm{H}, J=8.22$, 2.35, and $0.78 \mathrm{~Hz}$ ), $6.43(\mathrm{dd}, 1 \mathrm{H}, J=17.22$ and $1.56 \mathrm{~Hz}$ ), $6.16(\mathrm{dd}$, $1 \mathrm{H}, J=17.22$ and $10.17 \mathrm{~Hz}), 5.90-5.82(\mathrm{~m}, 2 \mathrm{H}), 5.79-5.67(\mathrm{~m}$, $1 \mathrm{H}), 5.13-5.05(\mathrm{~m}, 2 \mathrm{H}), 2.73-2.55(\mathrm{~m}, 2 \mathrm{H}) ;{ }^{13} \mathrm{C}$ NMR $(400 \mathrm{MHz}$, $\left.\mathrm{CDCl}_{3}\right) \delta 165.21,157.27,156.94,142.04,132.92,130.94,129.71$, 129.70, 128.41, 123.29, 121.22, 118.86, 118.23, 118.06, 116.80, 74.83, 40.72; Enantiomeric excess was found as 75\% with HPLCChiracel AD-H column (i-propanol/hexane 1:99, $1 \mathrm{~mL} / \mathrm{min}$ $t_{1}=4.50 \mathrm{~min}$ 'minor enantiomer', $t_{2}=4.80 \mathrm{~min}$ 'major enantiomer').

\subsubsection{7. (S)-(-)-1-(Naphthalen-2-yl)-but-3-enyl acrylate (16)}

Purification of the crude product by column chromatography on silica gel (ethyl acetate/hexane, 1:8) gave $124 \mathrm{mg}$ of $(S)-(-)-1-$ (naphthalen-2-yl)-but-3-enyl acrylate (16) with $73 \%$ yield. $R_{\mathrm{f}}=0.63$ (ethyl acetate/hexanes, $\left.1: 4\right) ;[\alpha]_{\mathrm{D}}^{27}-54.79\left(c \mathrm{l} 1.23, \mathrm{CH}_{2} \mathrm{Cl}_{2}\right)$; ${ }^{1} \mathrm{H}$ NMR (400 MHz, $\left.\mathrm{CDCl}_{3}\right) \delta 7.88-7.70(\mathrm{~m}, 4 \mathrm{H}), 7.53-7.41(\mathrm{~m}, 3 \mathrm{H})$, $6.44(\mathrm{~d}, 1 \mathrm{H}, J=17.3 \mathrm{~Hz}), 6.24-6.12(\mathrm{~m}, 1 \mathrm{H}), 6.09-6.00(\mathrm{~m}, 1 \mathrm{H}), 5.84$ $(\mathrm{d}, 1 \mathrm{H}, J=10.4 \mathrm{~Hz}), 5.80-5.67(\mathrm{~m}, 1 \mathrm{H}), 5.16-5.00(\mathrm{~m}, 2 \mathrm{H}), 2.85-$ $2.63(\mathrm{~m}, 2 \mathrm{H}) ;{ }^{13} \mathrm{C}$ NMR $\left(400 \mathrm{MHz}, \mathrm{CDCl}_{3}\right) \delta 165.74,137.64$, $133.49,133.45,133.44,131.28,128.92,128.65,128.41,128.01$, 126.56, 126.45, 126.10, 124.62, 118.56, 75.86, 41.00; MS (EI) $\mathrm{m} / z$ calculated for $\mathrm{M}^{+}\left(\mathrm{C}_{17} \mathrm{H}_{16} \mathrm{O}_{2}\right)=252,1$; found: 252 (2\%), 224, 178, 156 (100\%), 128, 68; Enantiomeric excess was found as $81 \%$ with HPLC-Chiracel AD-H column ( $i$-propanol/hexane 5:95, $1 \mathrm{~mL} / \mathrm{min}$ $t_{1}=3.21 \mathrm{~min}$ 'major enantiomer', $t_{2}=4.22 \mathrm{~min}$ 'minor enantiomer').
4.1.18. $(R)-(+)-5,6$-Dihydro-6-(naphthalen-2-yl)pyran-2-one (4)

To a stirred solution of $80.2 \mathrm{mg}$ of Grubbs' catalyst (10 $\mathrm{mol} \%$ ) in $8 \mathrm{~mL}$ dichloromethane at $60^{\circ} \mathrm{C}$ was added a solution of $205 \mathrm{mg}$ $(0.812 \mathrm{mmol})$ of $14 \mathbf{a}$ in $90 \mathrm{~mL}$ of dichloromethane. The resulting mixture was heated for $14 \mathrm{~h}$. At the end of this period, the mixture was cooled to room temperature and concentrated under reduced pressure. The crude was purified by column chromatography on silica gel (ethyl acetate/hexanes, 1:8) furnished $159 \mathrm{mg}(R)-5,6-$ dihydro-6-(naphthalen-2-yl)pyran-2-one (4) with 92\% yield. $R_{\mathrm{f}}=0.13$ (ethyl acetate/hexanes, $\left.1: 4\right) \cdot[\alpha]_{\mathrm{D}}^{20}+190.19\left(c 1.59, \mathrm{CH}_{2} \mathrm{Cl}_{2}\right)$. ${ }^{1} \mathrm{H}$ NMR $\left(400 \mathrm{MHz}, \mathrm{CDCl}_{3}\right) \delta$ 7.91-7.82 (m, 4H), 7.54-7.47 (m, 3H), 7.03-6.96 (m, 1H), $6.18(\mathrm{~d}, 1 \mathrm{H}, J=10.9 \mathrm{~Hz}), 5.63(\mathrm{dd}, 1 \mathrm{H}, J=10.7$, and $5.2 \mathrm{~Hz}), 2.80-2.64(\mathrm{~m}, 2 \mathrm{H}) ;{ }^{13} \mathrm{C}$ NMR $\left(400 \mathrm{MHz}, \mathrm{CDCl}_{3}\right) \delta$ $164.41,145.19,136.13,133.59,133.42,128.46,128.08,126.87$, $126.83,125.53,123.86,122.13,105.11,79.65,32.08$; MS (EI) $m / z$ calculated for $\mathrm{M}^{+}\left(\mathrm{C}_{15} \mathrm{H}_{12} \mathrm{O}_{2}\right)=224.1$; found: $224(50 \%), 178,156$ (100\%), 128, 68; HPLC - Chiracel AD-H column ( $i$-propanol/hexane $5: 95,1 \mathrm{~mL} / \mathrm{min} t_{1}=17.66 \mathrm{~min}$ 'major enantiomer', $t_{2}=18.27 \mathrm{~min}$ 'minor enantiomer').

\subsubsection{9. (R)-(+)-6-(Quinolin-3-yl)-5,6-dihydro-2H-pyran-2-one (5)}

The crude product was purified by column chromatography on silica gel (ethyl acetate/hexanes, $1: 6$ ) furnished $80 \mathrm{mg}$ of $(R)-(+)-6-$ (quinolin-3-yl)-5,6-dihydro-2H-pyran-2-one (5) as a yellow solid with $62 \%$ yield. $R_{\mathrm{f}}=0.11$ (ethyl acetate/hexanes, $\left.1: 2\right) . \quad[\alpha]_{\mathrm{D}}^{22}$ +205.76 (c 0.78, EtOH). ${ }^{1} \mathrm{H}$ NMR $\left(400 \mathrm{MHz}, \mathrm{CDCl}_{3}\right) \delta 8.92$ (d, $1 \mathrm{H}$ $J=1.96 \mathrm{~Hz}), 8.26(\mathrm{~s}, 1 \mathrm{H}), 8.12(\mathrm{~d}, 1 \mathrm{H}, J=8.22 \mathrm{~Hz}), 7.85(\mathrm{~d}, 1 \mathrm{H}$ $J=8.22 \mathrm{~Hz}), 7.78-7.72(\mathrm{~m}, 1 \mathrm{H}), 7.62-7.55(\mathrm{~m}, 1 \mathrm{H}), 7.06-6.99(\mathrm{~m}$, $1 \mathrm{H}), 6.20(\mathrm{dd}, 1 \mathrm{H}, J=9.78$ and $1.56 \mathrm{~Hz}), 5.73-5.66(\mathrm{~m}, 1 \mathrm{H}), 2.79-$ $2.73(\mathrm{~m}, 2 \mathrm{H}) ;{ }^{13} \mathrm{C}$ NMR $\left(400 \mathrm{MHz}, \mathrm{CDCl}_{3}\right) \delta 163.48,148.26$ $148.06,144.56,133.30,131.18,130.04,129.28,127.98,127.45$, 127.26, 121.83, 77.11, 31.52; Enantiomeric excess was found as 97\% with HPLC-Chiracel AD-H column ( $i$-propanol/hexane 5:95, $1 \mathrm{~mL} / \mathrm{min} t_{1}=27.46 \mathrm{~min}$ 'minor enantiomer', $t_{2}=33.19 \mathrm{~min}$ 'major enantiomer').

\subsubsection{0. (R)-(+)-6-(Naphthalen-1-yl)-5,6-dihydro-2H-pyran-2- one (6)}

The crude product was purified by column chromatography on silica gel (ethyl acetate/hexanes, 1:8) furnished $125 \mathrm{mg}$ of $(R)-(+)-$ 6-(naphthalen-1-yl)-5,6-dihydro-2H-pyran-2-one (6) as a light yellow solid with $75 \%$ yield. $\mathrm{R}_{\mathrm{f}}=0.14$ (ethyl acetate/hexanes, $1: 4$ ). $[\alpha]_{\mathrm{D}}^{23}+172.88\left(\right.$ c $\left.1.25, \mathrm{CH}_{2} \mathrm{Cl}_{2}\right) .{ }^{1} \mathrm{H}$ NMR $\left(400 \mathrm{MHz}, \mathrm{CDCl}_{3}\right) \delta 8.00-$ $7.82(\mathrm{~m}, 3 \mathrm{H}), 7.71(\mathrm{~d}, 1 \mathrm{H}, J=7.14 \mathrm{~Hz}), 7.58-7.45(\mathrm{~m}, 3 \mathrm{H}), 7.09$ $6.99(\mathrm{~m}, 1 \mathrm{H}), 6.25-6.17(\mathrm{~m}, 2 \mathrm{H}), 2.84-2.78(\mathrm{~m}, 2 \mathrm{H}) ;{ }^{13} \mathrm{C}$ NMR $\left(400 \mathrm{MHz}, \mathrm{CDCl}_{3}\right) \delta 164.54,145.49,134.07,133.99,130.16$, $129.41,128.38,126.85,126.07,125.61,124.39,122.72,121.89$, 76.71, 31.38; Enantiomeric excess was found as $11 \%$ with HPLCChiracel AD-H column (i-propanol/hexane 5:95, $1 \mathrm{~mL} / \mathrm{min}$ $t_{1}=15.50 \mathrm{~min}$ 'major enantiomer', $t_{2}=19.50 \mathrm{~min}$ 'minor enantiomer').

\subsubsection{1. $(R)-(+)-6-(Q u i n o l i n-4-y l)-5,6-d i h y d r o-2 H-p y r a n-2-o n e$ (7)}

The crude product was purified by column chromatography on silica gel (ethyl acetate/hexanes, 1:8) furnished $9 \mathrm{mg}$ of $(R)-(+)-6$ (quinolin-4-yl)-5,6-dihydro-2H-pyran-2-one (7) as a light yellow solid with $34 \%$ yield. $R_{\mathrm{f}}=0.14$ (ethyl acetate/hexanes, $\left.1: 1\right) .\left([\alpha]_{\mathrm{D}}^{26}\right.$ $+313.91\left(c 0.63, \mathrm{CH}_{2} \mathrm{Cl}_{2}\right)$ was detected for $86 \%$ ee in the second synthesis). ${ }^{1} \mathrm{H}$ NMR (400 MHz, $\left.\mathrm{CDCl}_{3}\right) \delta 8.91(\mathrm{~d}, 1 \mathrm{H}, \mathrm{J}=4.70 \mathrm{~Hz}), 8.15$ (dd, $1 \mathrm{H}, J=8.61$ and $0.78 \mathrm{~Hz}$ ), 8.01 (dd, $1 \mathrm{H}, J=8.61$ and $0.78 \mathrm{~Hz}$ ), 7.72 (ddd, $1 \mathrm{H}, J=8.22,6.65$ and $1.17 \mathrm{~Hz}$ ), 7.61-7.55 (m, $2 \mathrm{H}$ ), 5.96-5.85 (m, 1H), 5.57-5.52 (m, 1H), 5.27-5.21 (m, 2H), 2.82$2.74(\mathrm{~m}, 1 \mathrm{H}), 2.58-2.49(\mathrm{~m}, 1 \mathrm{H}) ;{ }^{13} \mathrm{C} \mathrm{NMR}\left(400 \mathrm{MHz}, \mathrm{CDCl}_{3}\right) \delta$ $150.33,149.20,148.26,133.73,130.37,129.06,126.57,125.35$, 
122.76, 119.21, 117.44, 68.85, 42.80, 29.67; Enantiomeric excess was found as $95 \%$ with HPLC-Chiracel AD-H column ( $i$-propanol/ hexane $5: 95,1 \mathrm{~mL} / \mathrm{min} t_{1}=6.42 \mathrm{~min}$ 'major enantiomer', $t_{2}=$ 7,15 min 'minor enantiomer').

\subsubsection{2. $(R)-(+)-6-(2-M e t h y l n a p h t h a l e n-1-y l)-5,6-d i h y d r o-2 H-$ pyran-2-one (8)}

The crude product was purified by column chromatography on silica gel (ethyl acetate/hexanes, 1:8) furnished $38 \mathrm{mg}$ of $(R)-(+)-6-$ (2-methylnaphthalen-1-yl)-5,6-dihydro-2H-pyran-2-one (8) as a light yellow oil with $60 \%$ yield. $R_{\mathrm{f}}=0.24$ (ethyl acetate/hexanes, 1:2). $[\alpha]_{\mathrm{D}}^{27}+136.79\left(\right.$ c $\left.0.31, \mathrm{CH}_{2} \mathrm{Cl}_{2}\right) .{ }^{1} \mathrm{H}$ NMR $\left(400 \mathrm{MHz}, \mathrm{CDCl}_{3}\right) \delta$ $8.22(\mathrm{~d}, 1 \mathrm{H}, J=8.61 \mathrm{~Hz}), 7.82(\mathrm{dd}, 1 \mathrm{H}, J=7.82$ and $1.57 \mathrm{~Hz}), 7.75$ $(\mathrm{d}, 1 \mathrm{H}, J=8.22 \mathrm{~Hz}), 7.50-7.40(\mathrm{~m}, 2 \mathrm{H}), 7.29(\mathrm{~d}, 1 \mathrm{H}, J=8.22 \mathrm{~Hz})$, 7.06 (ddd, $1 \mathrm{H}, J=9.78,6.26$, and $1.96 \mathrm{~Hz}$ ), 6.30 (dd, $1 \mathrm{H}, J=13.30$ and $4.30 \mathrm{~Hz}$ ), 6.23 (ddd, $1 \mathrm{H}, J=9.78,2.74$, and $1.17 \mathrm{~Hz}$ ), 3.27$3.15(\mathrm{~m}, 1 \mathrm{H}), 2.56(\mathrm{~s}, 3 \mathrm{H}), 2.55-2.44(\mathrm{~m}, 1 \mathrm{H}) ;{ }^{13} \mathrm{C}$ NMR $\left(400 \mathrm{MHz}, \mathrm{CDCl}_{3}\right) \delta 164.28,145.70,133.91,133.11,131.03$, $129.74,129.35,129.32,128.94,126.20,124.89,124.46,121.48$, 76.58, 29.48, 20.84; Enantiomeric excess was found as $100 \%$ with HPLC-Chiracel AD-H column ( $i$-propanol/hexane 5:95, $1 \mathrm{~mL} / \mathrm{min}$ $t_{1}=21.14 \mathrm{~min}$ 'single peak').

\subsubsection{3. $(R)-(+)-6-(4-M e t h y l n a p h t h a l e n-1-y l)-5,6-d i h y d r o-2 H-$ pyran-2-one (9)}

The crude product was purified by column chromatography on silica gel (ethyl acetate/hexanes, 1:8) furnished $27 \mathrm{mg}$ of $(R)-(+)-6-$ (4-methylnaphthalen-1-yl)-5,6-dihydro-2H-pyran-2-one (9) as a light yellow solid with $87 \%$ yield. $R_{\mathrm{f}}=0.15$ (ethyl acetate/hexanes, 1:4). $[\alpha]_{\mathrm{D}}^{28}+114.64\left(c 0.21, \mathrm{CH}_{2} \mathrm{Cl}_{2}\right) \cdot{ }^{1} \mathrm{H}$ NMR $\left(400 \mathrm{MHz}, \mathrm{CDCl}_{3}\right) \delta$ 8.10-8.03 (m, 1H), 8.01-7.95 (m, 1H), 7.61-7.52 (m, 3H), $7.35(\mathrm{~d}$, $1 \mathrm{H}, J=7.04 \mathrm{~Hz}), 7.06-6.99(\mathrm{~m}, 1 \mathrm{H}), 6.24-6.15(\mathrm{~m}, 2 \mathrm{H}), 2.83-2.76$ $(\mathrm{m}, 2 \mathrm{H}), 2.71(\mathrm{~s}, 1 \mathrm{H}) ;{ }^{13} \mathrm{C}$ NMR $\left(400 \mathrm{MHz}, \mathrm{CDCl}_{3}\right) \delta 164.38$, $145.27,135.44,132.83,131.96,130.03,126.18,126.10,125.64$, $125.14,123.88,123.01,121.59,76.79,31.08,19.61$; Enantiomeric excess was found as 93\% with HPLC-Chiracel AD-H column ( $i$-propanol/hexane $5: 95,1 \mathrm{~mL} / \mathrm{min} t_{1}=14.96 \mathrm{~min}$ 'major enantiomer', $t_{2}=17.64$ min 'minor enantiomer').

\subsubsection{4. (R)-(+)-6-(3-Phenoxyphenyl)-5,6-dihydro-2H-pyran-2- one (10)}

The crude product was purified by column chromatography on silica gel (ethyl acetate/hexanes, 1:8) furnished $35 \mathrm{mg}$ of $(R)-(+)-6-$ (3-phenoxyphenyl)-5,6-dihydro-2H-pyran-2-one (10) as a yellow solid with $91 \%$ yield. $R_{\mathrm{f}}=0.30$ (ethyl acetate/hexanes, $1: 2$ ). $[\alpha]_{\mathrm{D}}^{29}$ +115.0 (c $0.34, \mathrm{CH}_{2} \mathrm{Cl}_{2}$ ). ${ }^{1} \mathrm{H}$ NMR $\left(400 \mathrm{MHz}, \mathrm{CDCl}_{3}\right) \delta 7.39-7.30$ $(\mathrm{m}, 3 \mathrm{H}), 7.17-6.92(\mathrm{~m}, 7 \mathrm{H}), 6.12(\mathrm{ddd}, 1 \mathrm{H}, J=9.78,2.35$, and $1.56 \mathrm{~Hz}), \quad 5.45-5.37(\mathrm{~m}, 1 \mathrm{H}), \quad 2.70-2.55(\mathrm{~m}, 2 \mathrm{H}) ;{ }^{13} \mathrm{C} \mathrm{NMR}$ $\left(400 \mathrm{MHz}, \mathrm{CDCl}_{3}\right) \delta 163.80,157.57,156.75,144.74,140.39$, $130.03,129.80,123.53,121.61,120.69,118.99,118.74,116.40$, 78.77, 31.52; Enantiomeric excess was found as 77\% with HPLCChiracel AD-H column (i-propanol/hexane 5:95, $1 \mathrm{~mL} / \mathrm{min}$ $t_{1}=14.99 \mathrm{~min}$ 'minor enantiomer', $t_{2}=16.82 \mathrm{~min}$ 'major enantiomer').

\subsubsection{5. (S)-(-)-6-(Naphthalen-2-yl)-5,6-dihydro-2H-pyran-2- one (11)}

The crude product was purified by column chromatography on silica gel (ethyl acetate/hexanes, 1:8) furnished $78 \mathrm{mg}$ of (S)-(-)-6(naphthalen-1-yl)-5,6-dihydro-2H-pyran-2-one (11) as a colorless solid with $73 \%$ yield. $R_{\mathrm{f}}=0.13$ (ethyl acetate/hexanes, $1: 4$ ). $[\alpha]_{\mathrm{D}}^{20}$ -175.38 (c $\left.0.78, \mathrm{CH}_{2} \mathrm{Cl}_{2}\right) .{ }^{1} \mathrm{H}$ NMR $\left(400 \mathrm{MHz}, \mathrm{CDCl}_{3}\right) \delta 7.91-7.82$ $(\mathrm{m}, 4 \mathrm{H}), 7.54-7.47(\mathrm{~m}, 3 \mathrm{H}), 7.03-6.96(\mathrm{~m}, 1 \mathrm{H}), 6.18(\mathrm{~d}, 1 \mathrm{H}$, $J=10.9 \mathrm{~Hz}$ ), $5.63(\mathrm{dd}, 1 \mathrm{H}, J=10.7$ and $5.2 \mathrm{~Hz}), 2.80-2.64(\mathrm{~m}, 2 \mathrm{H})$; ${ }^{13} \mathrm{C}$ NMR $\left(400 \mathrm{MHz}, \mathrm{CDCl}_{3}\right) \delta 164.41,145.19,136.13,133.59$, $133.42,128.46,128.08,126.87,126.83,125.53,123.86,122.13$,
105.11, 79.65, 32.08; $\mathrm{MS}$ (EI) $\mathrm{m} / \mathrm{z}$ calculated for $\mathrm{M}^{+}$ $\left(\mathrm{C}_{15} \mathrm{H}_{12} \mathrm{O}_{2}\right)=224.1$; found: 224 (50\%), 178, 156 (100\%), 128, 68; Enantiomeric excess was found as $43 \%$ with HPLC-Chiracel AD-H column ( $i$-propanol/hexane $5: 95,1 \mathrm{~mL} / \mathrm{min} t_{1}=17.52 \mathrm{~min}$ 'minor enantiomer', $t_{2}=18.25$ min 'major enantiomer').

\subsection{Cell viability assays}

\subsubsection{MTT Test for compounds $1 \mathrm{a}, 4$, and 11}

Four cell lines including PC-3, DU145, LNCaP, and MCF-7 were obtained from the ATCC (USA) culture collection. Cells were cultured in RPMI-1640 (Invitrogen, USA) or DMEM (Invitrogen, USA) supplemented with $5-10 \%$ fetal bovine serum (Sigma, USA), by additions of $100 \mathrm{IU} / \mathrm{mL}$ penicillin and $1 \mu \mathrm{g} / \mathrm{mL}$ streptomycin. Cells were grown in humidified atmosphere with $5 \% \mathrm{CO}_{2}$ at $37^{\circ} \mathrm{C}$. Cytotoxic effects of compounds were analyzed by MTT assay which is based on the cellular reduction of the tetrazolium salt 3-(4,5dimethylthiazol-2-yl)-2,5-diphenyltetrazoliumbromide (MTT, Sigma Chemicals) to a purple formazan product by mitochondrial dehydrogenases of viable cells. Cell proliferation was determined by adding $0.5 \mu \mathrm{g} / \mathrm{mL}$ per well, prepared as a sterile stock-solution of $5 \mathrm{mg} / \mathrm{mL}$ in Dulbeccos-phosphate-buffered saline (Gibco), diluted 1:10 in medium prior to use. Medium was removed $4 \mathrm{~h}$ later and blue formazan crystals solubilized in $200 \mu \mathrm{L} 100 \%$ dimethylsulfoxate (DMSO) per well. Amounts of blue formazan product were quantified at 570-690 nm using a microplate reader (Versamax, Tunable Microplate Reader, USA). For all cell lines, strong correlations between numbers of cells present and amounts of MTT formazan product were observed. Each cell type was incubated with various doses of $\mathbf{1 a}, \mathbf{4}$, and $\mathbf{1 1}$ for $72 \mathrm{~h}$ at $37^{\circ} \mathrm{C}$ and subjected to MTT assays to measure $\mathrm{IC}_{50}$ values. The data were obtained from three independent assays using two wells for each assay. Cell viability was calculated as\% cell viability.

\subsubsection{MTT Test for compounds $5-10$ and $14 \mathrm{~b}-14 \mathrm{~g}$}

Human Prostat Cancer (PC-3) cell line was kindly provided by Assoc. Prof. Kemal S. Korkmaz (Ege University, Engineering Faculty, Department of Bioengineering), human breast cancer (MCF-7) cell line was obtained from Oğuz Bayraktar. PC-3 cells were maintained in Dulbecco's modified Eagle's medium (DMEM) containing $5 \%$ fetal bovine serum (FBS), $1 \mu \mathrm{g} / \mathrm{mL}$ streptomycin/100 IU/mL penicillin, MCF-7 cell line was maintained in Roswell Park Memorial Institute-1640 (RPMI-1640) containing 15\% FBS (BIO-IND), $1 \mu \mathrm{g} /$ $\mathrm{mL}$ streptomycin $/ 100 \mathrm{IU} / \mathrm{mL}$ penicillin incubated at $37{ }^{\circ} \mathrm{C}$ in the dark with $5 \% \mathrm{CO}_{2}$ humidified incubator and passaged when they reached $80-85 \%$ confluency. Cells used in experiments were maintained from 10th to 20th passages.

To investigate the cytotoxic activity of the compounds, $95 \mu \mathrm{l}$ of cell suspension was inoculated into 96-well microculture plates at $1 \times 10^{4}$ cells density per well in culture media containing FBS, penicillin/streptomycin. Compounds were dissolved in dimethyl sulfoxide (DMSO) (Sigma, USA), filter sterilized, diluted at the appropriate concentrations with the culture medium. In all wells, $1 \%$ DMSO concentration was fixed. Dilutions of compounds were freshly prepared before each experiment. After $24 \mathrm{~h}$ cultivation for cell attachment, extracts were added at final concentrations $50,25,1,0.5,0.1,0.05$, and $0.01 \mu \mathrm{M}$ for triplicate assay. Cells were treated with the extracts for $48 \mathrm{~h}$ and cytotoxic effects were determined by tetrazolium (3-(4,5-dimethylthiazol-2-yl)-2,5-diphenyl tetrazolium bromide) (Sigma, USA) based colorimetric assay. This method depends on the cleavage of tetrazolium salt to purple formazan crystals by mitochondrial enzymes of metabolically active cells. ${ }^{29}$ Briefly, $4 \mathrm{~h}$ before the end of incubation period, medium of the cells was removed and wells were washed by pre-warmed phosphate-buffered saline (PBS) to remove any trace of compounds and to prevent color interference while optical density determina- 
tion. MTT stock-solution $(5 \mathrm{mg} / \mathrm{mL})$ was diluted at $1: 10$ ratio into complete culture media, $100 \mu \mathrm{l}$ of MTT dilution was added into each well and incubated at $37^{\circ} \mathrm{C}$ in humidified atmosphere. After $3.5 \mathrm{~h}$ plates were centrifuged at $1800 \mathrm{rpm}$ for $10 \mathrm{~min}$ at room temperature to avoid accidental removal of formazan crystals. Crystals were dissolved with $100 \mu$ l DMSO. The absorbance was determined at $540 \mathrm{~nm}$. Results were represented as percentage cell viability.

\section{Acknowledgments}

We thank to Assoc. Prof. Dr. Kemal S. Korkmaz from Ege University, and Biotechnology and Bioengineering Research Central Research Laboratories at Izmir Institute of Technology for their help in evaluation of MTT tests. This work was supported by TUBITAK (The Scientific and Technological Research Council of Turkey, Project No. 105T429).

\section{References and notes}

1. Hlubucek, J. R.; Robertson, A. V. Aust. J. Chem. 1967, 20, 2199.

2. El-Zayat, A. E.; Ferrigni, N. R.; McCloud, T. G.; McKenzie, A. T.; Byrn, S. R.; Cassady, J. M. Chang C.: McLauglin, J. L. Tetrahedron Lett. 1985, 26, 955.

3. Jewers, K.; Blunden, G.; Wetchapinan, S.; Dougan, J.; Manchada, A. H.; Davis, J. B.; Kyi, A. Phytochemistry 1972, 11, 2025.

4. Ahmad, F. B.; Tukol, W. A.; Omar, S.; Sharif, A. M. Phytochemistry 1991, 30, 2430

5. Goh, S. H. Ee, G. C. L. Chuah, C. H. Wei, C. Aust. J. Chem. 1995, 48, 199.

6. Cavalheiro, A. J.; Yoshida, M. Phytochemistry 2000, 53, 811.
7. Kabir, K. E.; Khan, A. R.; Mosaddik, M. A. J. Appl. Ent. 2003, 127, 112.

8. Mosaddik, M. A.; Haque, M. E. Phytother. Res. 2003, 17, 1155.

9. Ali, A. M.; Mackeen, M. M.; Hamid, M.; Aun, Q. B.; Zauyah, Y.; Azimahtol, H. L. P.; Kawazu, K. Planta Med. 1997, 63, 81.

10. Pihie, A. H. L.; Stanslas, J.; Bin Din, L. Anticancer Res. 1998, 18, 1739.

11. Inayat-Hussain, S. H.; Osman, A. B.; Din, L. B.; Ali, A. M.; Snowden, R. T.; MacFarlane, M.; Cain, K. FEBS Lett. 1999, 456, 379.

12. Teoh, P. L.; Azimahtol, H. L. P. Malays. Appl. Biol. 1999, 28, 107.

13. Inayat-Hussain, S. H.; Annuar, B. O.; Din, L. B.; Ali, A. M.; Ross, D. Toxicol. In Vitro 2003, 17, 433.

14. Chien, A. L. T.; Pihie, A. H. L. J. Biochem. Mol. Biol. 2003, 36, 269.

15. de Fatima, A.; Kohn, L. K.; Antonio, M. A.; Carvalho, J.; Pilli, R. A. Bioorg. Med. Chem. 2005, 13, 2927.

16. Meenakshii, N.; Lee, A.; Azimahtol, H. L. P.; Hasidah, S. Malays. Appl. Biol. 2000 29, 121.

17. de Fatima, A.; Kohn, L. K.; Carvalho, J.; Pilli, R. A. Bioorg. Med. Chem. 2006, 14, 622.

18. Tsafe, N. U.; Said, M. S. M.; Rosli, R.; Din, L. B.; Lai, L. C. Mutat. Res. 2004, 562, 91.

19. Ramachandran, P. V.; Reddy, M. V. R.; Brown, H. C. Tetrahedron Lett. 2000, 41 583.

20. Quitschalle, M.; Christmann, M.; Bhatt, U.; Kalesse, M. Tetrahedron Lett. 2001 42, 1263

21. de Fatima, A.; Pilli, R. A. Arkivoc 2003, 10, 118 (d)

22. de Fatima, A.; Pilli, R. A. Tetrahedron Lett. 2003, 44, 8721.

23. Gruttadauria, M.; Lo Meo, P.; Noto, R. Tetrahedron Lett. 2004, 45, 83.

24. Sundby, E.; Perk, L.; Anthonsen, T.; Aasen, A. J.; Hansen, T. V. Tetrahedron 2004, $60,521$.

25. Liu, Z. Y.; Ji, J. X.; Li, B. G. J. Chem. Res. (S) 2004, 1, 61.

26. Cundy, K. C.; Crooks, P. A. J. Chromatogr. 1983, 281, 17.

27. Gawley, R. E.; Aube, J. Principles of Asymmetric Synthesis. In Baldwin, J. E., Ed.; Pergamon Press: Great Britain, 1996; pp 46-50. and references therein.

28. Stephani, R.; Cesare, V. J. Chromatogr. A 1998, 813, 79.

29. Ciapetti, G.; Cenni, E.; Paratelli, L.; Pizzoferrato, A. Biomaterials 1993, 14, 359. 